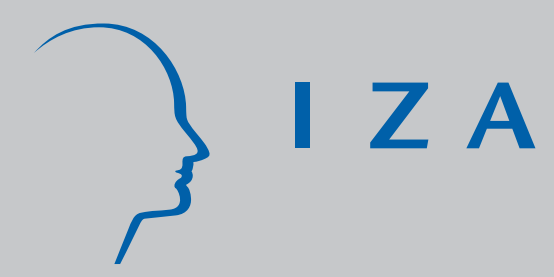

IZA DP No. 1977

Public Implementation Eliminates Detrimental Effects of Punishment on Human Cooperation

Erte Xiao

Daniel Houser

February 2006 


\title{
Public Implementation Eliminates Detrimental Effects of Punishment on Human Cooperation
}

\author{
Erte Xiao \\ George Mason University \\ and IZA Bonn \\ Daniel Houser \\ George Mason University
}

\author{
Discussion Paper No. 1977 \\ February 2006
}

\author{
IZA \\ P.O. Box 7240 \\ 53072 Bonn \\ Germany \\ Phone: +49-228-3894-0 \\ Fax: +49-228-3894-180 \\ Email: iza@iza.org
}

\begin{abstract}
Any opinions expressed here are those of the author(s) and not those of the institute. Research disseminated by IZA may include views on policy, but the institute itself takes no institutional policy positions.

The Institute for the Study of Labor (IZA) in Bonn is a local and virtual international research center and a place of communication between science, politics and business. IZA is an independent nonprofit company supported by Deutsche Post World Net. The center is associated with the University of Bonn and offers a stimulating research environment through its research networks, research support, and visitors and doctoral programs. IZA engages in (i) original and internationally competitive research in all fields of labor economics, (ii) development of policy concepts, and (iii) dissemination of research results and concepts to the interested public.
\end{abstract}

IZA Discussion Papers often represent preliminary work and are circulated to encourage discussion. Citation of such a paper should account for its provisional character. A revised version may be available directly from the author. 


\section{ABSTRACT}

\section{Public Implementation Eliminates Detrimental Effects of Punishment on Human Cooperation ${ }^{*}$}

Development of human societies requires cooperation among unrelated individuals and obedience to social norms. Although punishment is widely agreed to be potentially useful in fostering cooperation, many recent results in psychology and economics highlight punishments' failures in this regard ${ }^{1-4}$. These studies ignore punishments' social effects, and particularly its role in promoting social norms. We show here, using experiments with human subjects, that public implementation of punishment can eliminate its detrimental effects on cooperation. In a public goods game designed to create tension between group and individual interests ${ }^{5}$, we find that privately implemented punishment reduces cooperation relative to a baseline treatment without punishment. However, when that same incentive is implemented publicly, but anonymously, cooperation is sustained at significantly higher rates than in both baseline and private punishment treatments. These data support our hypothesis that public implementation of punishment enhances the salience of the violated social norm to both the punished and those who observed the punishment, and that this increased salience positively affects group members' norm obedience. Our findings point to the importance of accounting for social consequences of punishment when designing procedures to deter misconduct in social environments including schools, companies, markets and courts.

JEL Classification: C92, D71, H41

Keywords: punishment, cooperation, public goods game, social norms, experiments, behavioral economics

Corresponding author:

Daniel Houser

ICES, George Mason University

4400 University Drive MSN 1B2

Fairfax, VA 22030

USA

Email: dhouser@gmu.edu

\footnotetext{
* The authors contributed equally to this research. We are grateful to Rachel Croson and Ernst Fehr for valuable comments. We thank participants at the 2005 Economic Science Association and Southern Economic Association meetings for helpful remarks, and Xiaorong Zhou for assistance with the software. We gratefully acknowledge that the International Foundation for Research in Experimental Economics and the National Science Foundation supported this research.
} 
Humans use punishment to enforce cooperation in social and economic exchange ${ }^{6-8}$. When punishment is sufficiently severe, so that it overwhelms the expected benefit of defection, opportunistic behavior can be prevented ${ }^{9-13}$. However, as a practical matter, punishments severe enough to deter misconduct are often costly to implement, leaving them inefficient and often infeasible. Weak punishment, which occurs when its cost is less than the benefit to violating, is both feasible and credible. However, it can have detrimental effects on cooperation ${ }^{1-4,14}$. Previous research suggests this might be due to external incentives "crowding-out” preferences for norm-based behaviors ${ }^{2-4,15}$.

Social norms can be effective motivational mechanisms ${ }^{16}$, and the efficacy with which social norms direct behavior increases in the degree to which they are focal at the time of action ${ }^{17}$. In relation to private implementation, publicly implemented punishment can be more effective in promoting social norm salience, as public punishment emphasizes the norm to both violators and observers. We hypothesize that, particularly when incentives are weak, the social norm saliency effect will leave public punishment significantly more effective than private punishment at promoting cooperation.

Unlike its private counterpart, publicly implemented punishments can shame punishees $^{18}$. Shame can have significant effects on human behavior ${ }^{19-22}$, and many public punishment systems in the naturally occurring world attempt to avoid shame by announcing a punishment, but keeping the punishee anonymous ${ }^{23}$. We here report evidence that, absent any effects that might stem from shame, publicly implemented punishment promotes cooperation more efficiently than private punishment. 


\section{Design of Experiment}

We design a novel public goods game to test the hypothesis that publicly implemented weak punishment is more effective at promoting cooperation than an otherwise identical privately implemented sanction. The experiment consists of a baseline treatment without punishment, and one private and one public punishment treatment. We recruited 24 subjects for each treatment. To focus on norm salience effects, our design mitigates possible influences from shame and learning. In particular, we keep subjects anonymous and provide them, in the two punishment treatments, with full information regarding both the magnitude and likelihood of punishment (see Methods).

Subjects make decisions in groups of four, which remain fixed for the 30 rounds of each game. In the baseline treatment, each subject receives an endowment of 10 experimental dollars (E\$) per round and chooses, simultaneously with other subjects, non-negative integer amounts to invest in individual and group accounts. At each round's end, each E\$ in the individual account is worth one E\$ to the investor, and each E\$ in the group account yields $0.5 \mathrm{E} \$$ to each group member. Individual earnings are maximized by contributing zero to the group account. Group earnings are maximized when all subjects fully cooperate by contributing everything to the group account.

Punishment treatments are identical to the baseline except that subjects know each round has a 50\% chance of being monitored. If the round is monitored then that round's lowest group investor's earnings are reduced by a small amount that is increasing in the difference between her and her group members’ average contributions to the group account (see Methods). Earnings reductions are not redistributed to others, and other group members bear no punishment cost. 
The maximum expected penalty occurs when a subject makes a zero contribution and her group members contribute everything. In this case, there is a $50 \%$ chance that the low contributor receives a $10 \%$ reduction in that round's earnings. This punishment scheme is weak: contributing zero yields highest expected per-round earnings regardless of others' decisions.

Economic incentives in the public and private treatments are identical. The only difference between these treatments is that in the public treatment all members of a group are told when a round was monitored, as well as the amount (possibly zero) of the resulting punishment. When punishment is private, only the punishee knows that a round was monitored. There are no other information asymmetries. In particular, along with other information, subjects are given an anonymous list of their group members’ contributions, ordered from highest to lowest, in all treatments including the baseline (see Methods).

\section{Effects of Public and Private Punishment on Cooperation}

Figure 1 details the round-by-round mean contribution to the group account in the baseline and two punishment treatments. Data in the baseline treatment replicate typical findings ${ }^{5}$. In particular, contributions begin around 2/3 of the endowment and decline to about $1 / 3$ by round 30 . Also, subjects knew the game included exactly 30 rounds, and significant decay in cooperation over the last several rounds is apparent.

Cooperation in the two punishment treatments provides approximate bounds for cooperation in the baseline. In the private punishment treatment, cooperation is below baseline every round. It decays more quickly and falls further: by the final round, average 
contributions are $1 / 5$ of endowment. In contrast, cooperation in the public treatment is above baseline in 26 of 30 rounds. Strikingly, outside of the last several rounds, there is no apparent decay in cooperation in the public punishment treatment (Fig. 1).

To provide statistical support for these observations we regressed the average percentage contribution to the group account on a constant, the round and the lagged contribution (see Methods). Including end-game and start-game (learning the computer interface) effects introduces non-stationarities that bias inferences. We avoid this bias by focusing our analysis on rounds six through 25 in all cases. Including all of the data does not change inferences regarding our hypotheses (see Methods).

Table 1 details the results of our analysis. First, the round and lag coefficients are jointly statistically significantly different between any two treatments (two-tailed F-tests, $p=0.01$ in public vs. baseline, and $p<0.001$ in both other cases). This implies the patterns in the data are statistically significantly different among treatments. Also, the lag and round coefficients are jointly statistically significant for both the baseline and private treatments (two-tailed F-tests, $p<0.001$ in both cases). This implies statistically significant decay in cooperation in these cases. In contrast, the lagged contribution and the round are not jointly significantly different from zero (two-tailed F-test, $p=0.06$ ) in the public punishment treatment. Thus, as implied by visual inspection, we find no statistical evidence of cooperative decay in the public punishment treatment.

For each treatment we calculated the mean proportion of times that subjects contributed their full endowment to the group account, and the proportion of times that subjects contributed zero, over all 30 rounds (Fig. 2). Compared to baseline, private punishment is associated with a significant decrease in the proportion of full cooperation: 
it occurs with less than one-tenth the baseline frequency (3\% and 34\%, respectively, $p=0.01$, two-tailed Mann-Whitney test). This result is consistent with the hypothesis that external incentives crowd out internal motivations ${ }^{2,3,15}$, leaving subjects less willing to cooperate voluntarily. However, while the extents of zero and full cooperation under public punishment are lower than baseline (10\% vs. $21 \%$, and $27 \%$ vs. $34 \%$, respectively), neither difference is significant $(p=0.15$ and $p=0.52$, respectively, two-tailed MannWhitney test).

\section{Availability Heuristic and Public Punishment}

Publicly implemented punishment promotes social norms to both punishees and observers, and this is one explanation for its ability to foster cooperation. An alternative explanation, which is independent of a social norm effect, appeals to the "availability heuristic” ${ }^{24-26}$. The argument is that publicly implemented punishment leads people to form incorrect subjective beliefs that the likelihood of punishment is higher than its actual (known) probability, and this can increase cooperation. In our case the punishment is so small that, even if implemented with probability one, the earnings maximizing strategy is to free-ride. Nevertheless, people need not hold earnings maximizing preferences. For example, if people are sufficiently "punishment-averse," then even small increases in the chance of punishment could increase cooperation.

To obtain evidence on the availability heuristic explanation, we conducted a private punishment treatment that is identical to the earlier private treatment, except that monitoring occurred every round with probability one, and subjects were told this was the case. The results of this treatment are nearly identical to the earlier private punishment 
case (Fig. 3). This casts doubt on the availability heuristic as an independent explanation for high cooperation under public punishment.

\section{Discussion}

Punishment often arises in a social context, and humans are affected by events both experienced and observed. Previous research, however, has not clarified behavioral effects tied to observing another's punishment. This is despite the fact that such effects are likely to be economically significant. For example, in the case of punishment in organizations, there are many more observers than punishees, and observers typically include highly committed and productive workers ${ }^{23}$.

Our analysis did not explore factors such as shame effects ${ }^{19-22}$, learning effects ${ }^{27}$,

justice judgments and emotional responses to the punishees ${ }^{28-30}$, all of which could influence punishment's efficacy. In this context, our results indicate that punishment is more efficacious when it is implemented in a way that promotes social norms. This finding provides an efficiency rationale for social evolution to legal justice systems, as opposed for example to those based on private enforcement by vigilantes. More broadly, our results offer novel insights that are valuable to all who wish to deter misconduct through punishment. 


\section{Methods}

\section{Experiment Procedures}

Our treatments include a baseline linear public goods game without punishment opportunities and three treatments with punishment. Exactly 96 subjects participated in the experiment with 24 subjects in each of four treatments. Each treatment was run in two groups of 12 subjects each on two separate days. All subjects were recruited from George Mason University’s general student population, using electronic recruiting procedures. Subjects earned \$5 for arriving to the session on time. Subjects earned E\$ during the experiment, and at the end of the experiment the E\$ were exchanged for dollars at the rate of $20 \mathrm{E} \$=\$ 1$. On average, subjects were in the lab for about 90 minutes. Mean earnings were $\$ 22$ plus the on-time bonus.

In the first round of each session, 12 subjects are randomly placed in groups of four and told they will be in the same group for the entire experiment. Subjects read computerized instructions and answer embedded questions. The experiment starts after all subjects finish the instructions. After each group member makes an investment decision, each subject is informed of her round's earnings, and is told her other group members' contributions. Her members' contributions are listed from highest to lowest. The identities of her group members are not revealed, and it is not possible to track any particular member's contributions over time. Subjects are told the difference between their group account contribution and the average contribution of their other group members. It is worthwhile to emphasize that all the above information is provided in each treatment, in order to avoid confounds due to systematic differences in subjects’ information. 
As the experiment proceeds, all of the information subjects received at the end of each round is preserved in a "History" box. Subjects can access previous rounds' decisions and results at any time.

In each round of the punishment treatments, after all members have made their investment decisions, subjects see a "Payoff Cut Information” box on their screen. The message in the box differs by treatment. In the private punishment treatment, when the round is monitored, the punishee sees "In this round, your payoff was cut by X\% (Y E\$)", where $\mathrm{X}$ and $\mathrm{Y}$ are the appropriate numbers. The other members see "In this round, your payoff was not cut”. In the private punishment treatment, when the round is not monitored, all group members are informed "In this round, your payoff was not cut".

In the public punishment treatment when the round is monitored, the punishee is informed, "In this round, your payoff was cut by X\% (Y E\$)". The other members are told, "In this round, the payoff of a lowest Group Account investor (NOT you) was cut by $\mathrm{X} \%$ (Y E\$)”. In the public punishment treatment when the round is not monitored, all group members are informed "In this round, no one’s payoff was cut”.

Subjects know how punishment amounts are determined. If a round is monitored and a subject is punished, then the punishment amount is equal to Z\% of the punished subject's earnings that round, where $\mathrm{Z}=$ (average contribution to group account by the three other group members - punished subject's contribution). So, for example, if a punished subject had contributed zero to the group account, and all of his group members had contributed everything, then that subject would have that round's earnings reduced by $10 \%$. Note that this is about $1 / 10$ the level that successfully enforces cooperation in other studies ${ }^{9}$. If multiple subjects tie for the lowest contribution in a monitored round, 
then one of those lowest contributors is randomly selected to be sanctioned, and the others' earnings are not affected.

When punishment is implemented with probability 0.5 , the monitored rounds are predetermined by a random process and kept fixed throughout all treatments. In all punishment treatments, subjects are given full information about both the nature and likelihood of punishment, so our experiment mitigates learning effects. Anonymity is protected in order to mitigate shame effects.

\section{Analysis}

In the regression analysis reported in Table 1, we initially included separate intercepts, round and lag effects for each treatment. Because there are no statistical differences in intercepts among treatments (two-tailed F-test, $p=0.18$ ), they are collapsed into a single constant. Also, due to start and end-game effects, our analysis excludes the first and last five rounds of data from all treatments. Including these data do not change the substance of the results reported in the paper. In particular, cooperative decay in the public treatment is now statistically significant (two-tailed F-test, $p<0.001$ ), but is statistically significantly less than decay in the baseline treatment (two-tailed F-test, $p<0.001$ ), which itself is statistically significantly less than found in the private punishment treatment (two-tailed F-test, $p<0.001$ ). 


\section{References}

1. Fehr, E. \& Rockenbach, B. Detrimental effects of sanctions on human altruism. Nature 422, 137-140 (2003).

2. Frey, B.S. \& Jegen, R. Motivation Crowding Theory: A survey of empirical evidence. Journal of Economic Survey 15(5), 589-611 (2001).

3. Fehr, E. \& Falk, A. Psychological Foundations of Incentives. European Economic Review 46 687-724 (2002).

4. Gneezy, U. \& Rustichini, A. A Fine Is A Price. Journal of Legal Studies 29(1), 1-17(2000).

5. Ledyard, J.O. Public Goods: A Survey of Experimental Research. in A Handbook of Experimental Economics, ed. Roth, A. \& Kagel, J. (Princeton: Princeton University Press, 111-194, 1995).

6. Fehr, E.\& Fischbacher, U. Social norms and human cooperation. TRENDS in Cognitive Sciences 8 (4), 185-190 (2004).

7. Camerer, C. Behavioral Game Theory: Experiments in Strategic Interaction. (Princeton University Press, Princeton, NJ, 2003).

8. Xiao, E. \& Houser, D. Emotion Expression in Human Punishment Behavior. Proceedings of the National Academy of Sciences 102(20), 7398-7401(2005).

9. Fehr, E. \& Gächter,S. Cooperation and Punishment in Public Goods Experiments. American Economic Review 90(4), 980-994 (2000).

10. Andreoni, J., Harbaugh, W. \&Vesterlund, L. The Carrot or Stick: Reward, Punishment and Cooperation. American Economic Review 93, 893-902 (2003).

11. Fowler, J.H. Altruistic punishment and the origin of cooperation, Proceedings of National Academy of Sciences 102, 7027-49 (2005).

12. Yamagishi, T. Seriousness of Social Dilemmas and the Provision of a Sanctioning System. Social Psychology Quarterly 51(1), 32-42 (1988).

13. Ostrom, E., Walker, J. \& Gardner, R. Covenants With and Without a Sword: Self-Governance is Possible. American Political Science Review 86, 404 - 417(1992).

14. Bohnet, I., Frey, B.S. \& Huck, S. More order with less law: on contract enforcement, trust and crowding. Am. Pol. Sci. Rev. 95, 131-144 (2001).

15. Deci, E., Koestner, R. \& Ryan, R. A meta-analytic of experiments examining the effects of extrinsic rewards on intrinsic motivation. Psychological Bulletin 125(6), 627-668 (1999).

16. Elster, J. Social Norms and Economic Theory. Journal of Economic Perspectives 3(4), 99-117, 1989.

17. Kallgren, C.A., Reno, R.R. \& Cialdini, R.B. A Focus Theory of Normative Conduct: When Norms Do and Do Not Affect Behavior. Personality and Social Psychology Bulletin 26 (8), 1002-1012 (2000).

18. Smith, R.H., Webster, J.M., Parrot, W.G. \& Eyre, H.L. The Role of Public Exposure in Moral and Nonmoral Shame and Guilt. Journal of Personality \& Social Psychology 83, 138 -159 (2002).

19. Lewis, H.B. Shame and guilt in neurosis.( International University Press. New York, 1971).

20. Elster, J. Alchemies of the Mind: Rationality and the Emotions (Cambridge, 1999)

21. Whitman, J.Q. What is Wrong with Inflicting Shame Sanctions? Yale Law Journal 107(5), 1055-1092(1998)

22. Rush, B. An Enquiry into the Effects of Public Punishments upon Criminals and upon Society. Negley K. Teeters, ed., A Plan for the Punishment of Crimes by Benjamin Rush, M. D., 1746-1813 (Philadelphia: The Pennsylvania Prison Society, 1954)

23. Trevino, L.K. \& Ball, G.A. The social implications of punishing unethical behavior: observers' cognitive and affective reactions. Journal of Management 18(4), 751-768 (1992).

24. Tversky, A., \& Kahneman, D. Availability: a heuristic for judging frequency and 
probability. Cognitive Psychology 5, 207-232(1973)..

25. Croson, R. \& Sundali, J. The Gambler's Fallacy and the Hot Hand: Empirical Data from Casinos. Journal of Risk and Uncertainty 30(3), 195-209 (2005).

26. Camerer, C. Does the Basketball Market Believe in the 'Hot Hand'? American Economic Review 79, 1257-1261(1989).

27. Bandura, A. Social Learning Theory. (New York: General Learning Press, 1977).

28. Ball, G.A., Trevino, L.K. \& Sims, H.P. JR. Just and Unjust Punishment: Influences on subordinate performance and citizenship. Academy of Management Journal 37(2), 299322(1994).

29. Lind, E. A. \& Tyler, T. R. The social psychology of procedural justice. (New York: Plenum Press, 1988).

30. O’Reilly, C. A. III \&Puffer, S. M. The impact of rewards and punishments in a social context: A laboratory and field experiment. Journal of Occupational Psychology 62, 41-55(1989). 
Table 1. Contribution Dynamics: Regression Results

\begin{tabular}{lc}
\hline \hline & $\begin{array}{c}\text { Average contribution } \\
\text { Independent Variables }\end{array}$ \\
\cline { 2 - 2 } & Coefficient \\
\hline $\mathrm{t} \cdot$ Baseline & -0.63 \\
$\mathrm{t} \cdot$ Public & $(0.31)$ \\
$\mathrm{t} \cdot$ Private & -0.13 \\
& $(0.12)$ \\
$\mathrm{C}_{\mathrm{t}-1} \cdot$ Baseline & -0.98 \\
& $(0.25)$ \\
$\mathrm{C}_{\mathrm{t}-1} \cdot$ Public & 0.28 \\
& $(0.13)$ \\
$\mathrm{C}_{\mathrm{t}-1} \cdot$ Private & 0.27 \\
$\mathrm{C}_{\mathrm{C}}$ Constant & $(0.15)$ \\
& 0.10 \\
$\mathrm{R}^{2}$ & $(0.19)$ \\
\hline
\end{tabular}

Notes: $\mathrm{N}=57$. Dependent variable $\mathrm{C}_{\mathrm{t}}$ is the overall average percentage contributed to the public account in round t by treatment. Robust standard errors are in parentheses. To avoid biases due to early and end-game effects, analysis includes data from rounds $t=6, \ldots ., 25$. Baseline $=1$ for the baseline treatment and is 0 otherwise. Public $=1$ for the public punishment treatment and is 0 otherwise. Private $=1$ for the private punishment treatment and is 0 otherwise. 


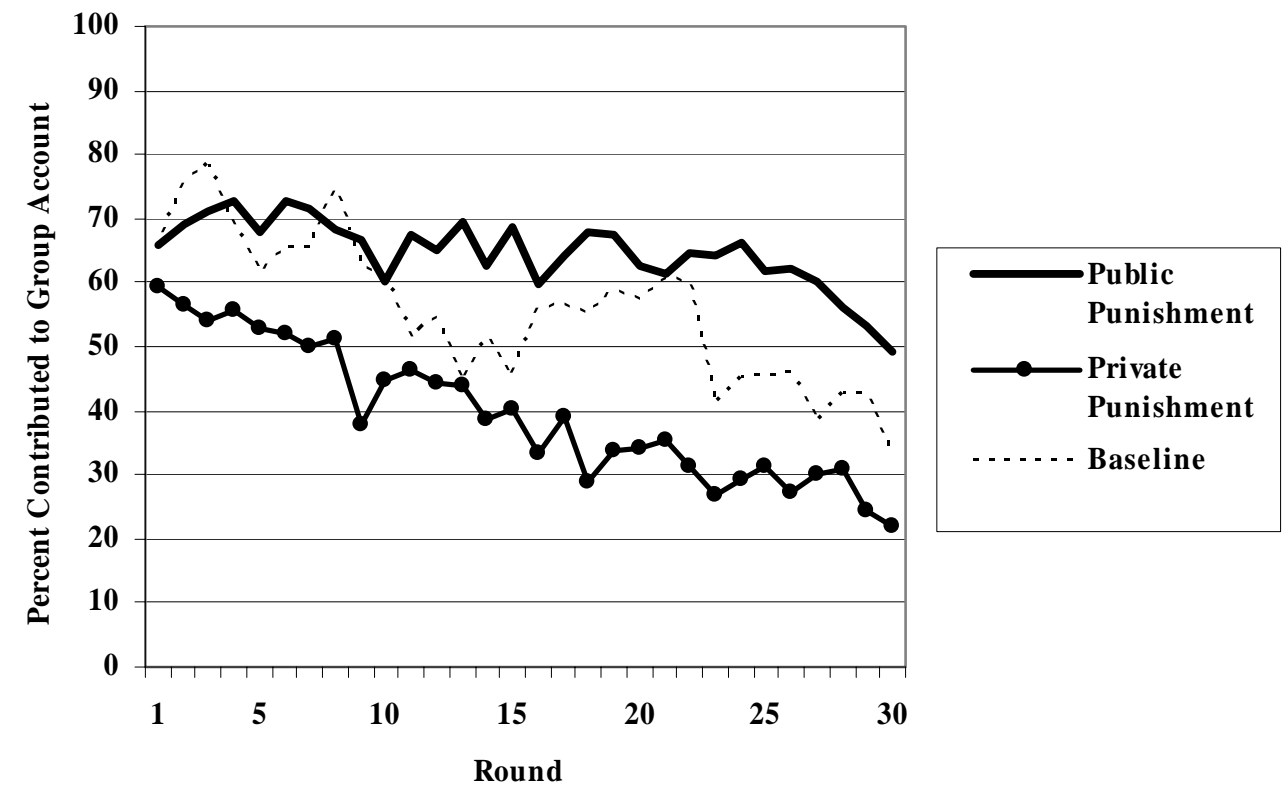

Figure 1. Mean group account contribution by round and treatment. Lowest contributors in the punishment treatments risk small sanctions. Sanctions are sufficiently small that in all three treatments each subject maximizes per-round earnings by contributing zero to the group account regardless of others' decisions, but the social optimum occurs when all group members contribute everything. Cooperation in the baseline treatment without punishment opportunities begins at about $2 / 3$ of the endowment, and then decays. The baseline decay rate falls between decay rates in the two punishment treatments. Cooperation is lowest when incentives are privately implemented and greatest when the cooperation norm is socially promoted through public, but anonymous, implementation of sanctions. 


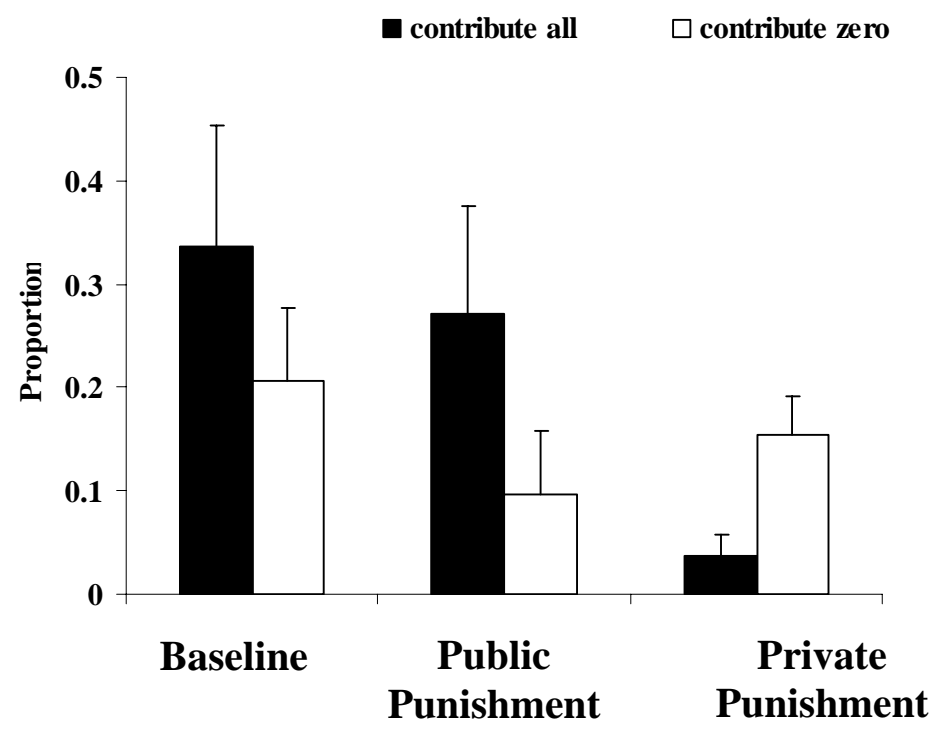

Figure 2. Effect of treatment on full cooperation $(\mathbf{1 0 0 \%}$ contribution) and perfect free-riding ( $0 \%$ contribution). Rates of $0 \%$ and $100 \%$ contributions by treatment (mean \pm s.e.m.) where the group is the unit of observation (six groups per treatment.) Freeriding is statistically identical among treatments. The propensity to contribute everything to the group account is significantly lower in the private treatment than in the other two treatments ( $p=0.01$ and $p=0.02$ in the Baseline and Public treatments, respectively, twotailed Mann-Whitney tests in both cases.) This suggests propensities to cooperate voluntarily can be reduced by incentives, but this effect can be eliminated if the incentive is applied publicly so that it promotes the cooperation norm. 


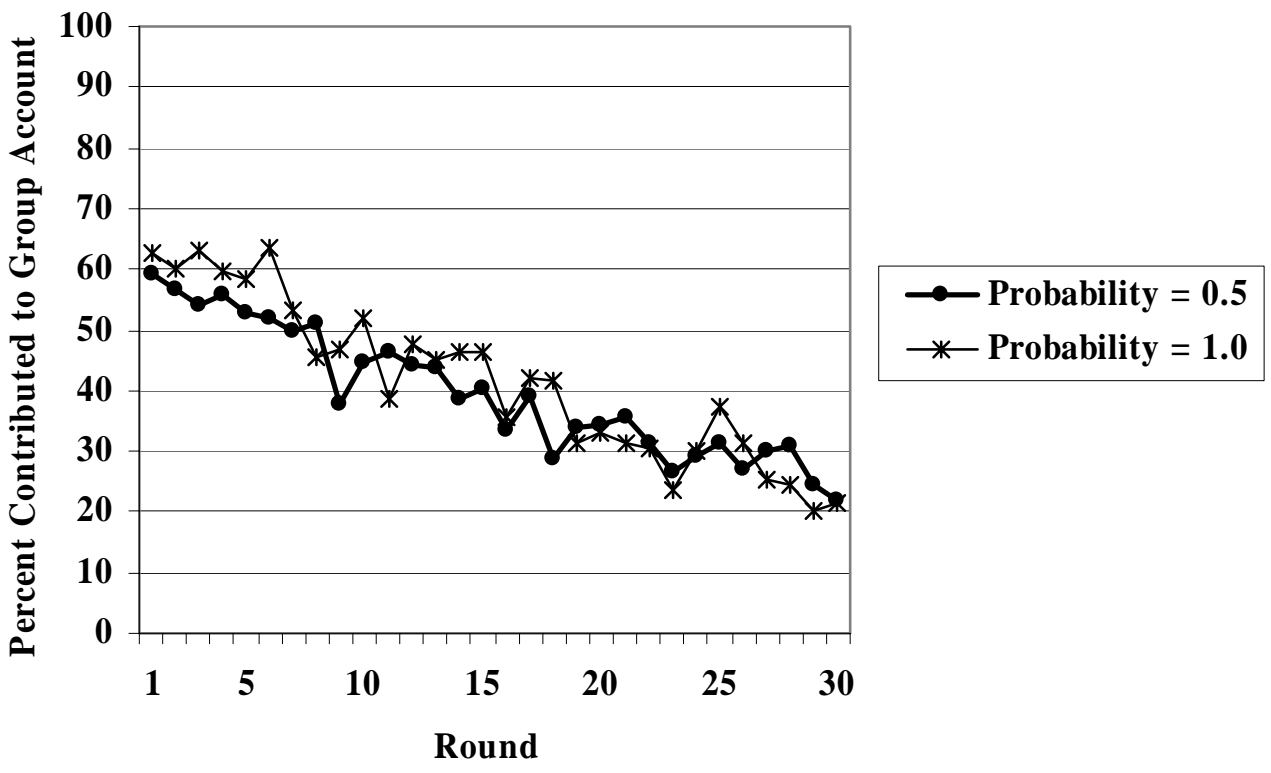

Figure 3. Mean Group Account Contribution in Private Punishment Treatments.

Sanctions in both treatments were implemented privately. Sanctions are sufficiently small that in both treatments subjects maximize per-round earnings by contributing zero to the group account, regardless of others' decisions. The social optimum occurs when all group members fully cooperate by contributing everything. Propensities to cooperate are not affected by changing the probability of punishment from 0.5 to 1.0 . This casts doubt on the "availability heuristic" as an explanation for increased cooperation in the public punishment treatment. It provides convergent support for our hypothesis that public punishment promotes social norms and, through this channel, fosters cooperation. 


\section{Appendix A.}

\section{Private Punishment Treatment}

Thank you for coming! You've earned \$5 for showing up on time, and the instructions explain how you make decisions to earn more money. So please read these instructions carefully! There is no talking at any time during this experiment. If you have a question please raise your hand, and an experimenter will assist you.

The experiment is divided into different rounds. In all, the experiment consists of 30 rounds. You will be randomly assigned to a group with 3 other participants. The composition of each group will NOT change during the experiment. You won't know the identities of your group members.

At the beginning of each round each participant receives $10 \mathbf{E \$}$. At the end of the experiment the total number of $\mathrm{E} \$$ you have earned will be converted to dollars at the following rate:

$$
20 \mathrm{E} \$=\$ 1
$$

In each round, you will decide how to allocate your E\$s. After each member in your group makes her decision, the computer will randomly decide whether to monitor the group this round or not. If the group is monitored, then one person in that round might receive a payoff cut. Additional information about the monitoring and payoff cuts is given below.

At the beginning of each round, you decide how many of your 10 E\$ to invest in the Group Account(G) and how many to invest in your Individual Account ( I ). These two accounts are explained below.

\section{Individual Account ( I)}

Every E\$ you assign to the Individual account will return one $\mathrm{E} \$$ at the end of the round. For example, if you invested all 10E\$ in your Individual account, you would earn 10E $\$$ from the individual account at the end of the round. If you invested 5E\$ in your Individual account, you would earn 5E\$ from the individual account at the end of the round.

\section{Group Account (G)}

Your earnings from the Group Account depend on the number of E\$ that you and your other group members invest in the Group Account. All E\$s that you and your group members invest in the Group account are added together and form the group investment. The group investment generates return of $2 \mathrm{E} \$$ for every one $\mathrm{E} \$$ invested. These earnings are then divided equally among all group members. Your group has $\mathbf{4}$ members (including yourself). So, every E\$ invested in the Group account will return half of an E\$ to each group member at the end of the round.

Some examples of returns to group investment are illustrated in the table below. The left column lists various amounts of group investment; the right column contains the corresponding personal earnings for each group member: 
Total Group investment amount

by your group (TG)
Return to each group member

(from Group investment)

\begin{tabular}{cc}
\hline 0 & 0 \\
8 & 4 \\
10 & 5 \\
14 & 7 \\
28 & 14 \\
40 & 20 \\
\hline
\end{tabular}

As you can see, it does not matter who invests $E \$ s$ in the Group account. Everyone will get the same return from every $\mathrm{E}$ \$ invested there-whether they invested $\mathrm{E} \$$ in the Group account or not.

\section{Monitoring}

After all members of your group have made their decisions, the computer will randomly decide whether to monitor the round. Each round has a $50 \%$ chance of being monitored, and whether a round is monitored does not depend on whether other rounds were or were not monitored.

Here is what monitoring means. If the round is monitored, then the lowest investor in the Group Account will have his or her payoff for that round cut by some amount. If two or more group members invest the same lowest amount in the Group Account, then the computer will randomly choose one of them to receive the payoff cut. If all the group members invest all their $10 \mathrm{E} \$$ to the Group account, no one will receive a payoff cut when the round is monitored.

\section{Payoff cut}

Here is how the payoff cut amount is determined. When a subject's payoff is cut, his or her payoff in that round will be reduced by a certain percentage. This percentage is determined by the difference between his/her Group investment (G) and the average Group investment of his/her other three group members (OG). The specific formula used to determine the amount of the payoff cut is:

Payoff cut Percentage $=($ OG-G) $\%$

Payoff Cut $=$ Original Payoff (before cut) $\times$ Payoff cut Percentage

You have been given a chart that shows the payoff cut percentage for different values of $\mathbf{G}$ and OG. From the chart you can see that the payoff cut percentage becomes increasingly larger as G becomes increasingly smaller than OG. Please raise your hand if you do not understand this chart.

Example: If a subject receives a payoff cut, his/her Group investment is 2 and other three members' average Group investment is 6, then his/her payoff cut percentage will be $(6-2) \%=4 \%$. You can double check this answer with the chart. It shows that when OG-G=4, the payoff cut percentage $=4 \%$. This means that $4 \%$ of the subject's original payoff (for that round only) will be cut. 
If a subject receives a payoff cut, his/her Group investment is 1 and other three members' average Group investment is 7, then his/her payoff cut percentage will be (7-1)\%=6\%. You can double check with the chart which shows that when $\mathbf{O G - G}=6$, the payoff cut percentage $=6 \%$. This also means that $6 \%$ of the original payoff will be cut in that round.

\section{Important: Each round you will only be told whether you received a payoff cut. No group members will know if any other group member's payoff was cut.}

\section{Your earnings in each round}

The total E\$s you earn at the end of each round is the sum of your earnings from each of the two accounts:

1) $\mathrm{E} \$ \mathrm{~s}$ earned from your Individual account = amount of $\mathrm{E} \$ \mathrm{~s}$ you invest in the Individual account.(I)

2) $\mathrm{E} \$$ s earned from the Group account $=0.5 \times$ the total invested $\mathrm{E} \$ \mathrm{~s}$ of all 4 Group members to this account.(TG)

So your earnings at the end of each round $=$

I $+0.5 \times$ TG, if there is no payoff cut, and

I + 0.5×TG - Payoff Cut amount, if there is a payoff cut.

\section{Example}

Suppose that you invested $8 \mathrm{E} \$ \mathrm{~s}$ in your Individual account and $2 \mathrm{E} \$ \mathrm{~s}$ in the Group account, and the three other members invested a total of $18 \mathrm{E} \$ \mathrm{~s}$ in the group account. This means there is a total of $20 \mathrm{E} \$ \mathrm{~s}$ in the group account. Then your earnings from the Group account would be $20 * 0.5=10 \mathrm{E} \$$. Each other subject in your group would also earn $10 \mathrm{E} \$ \mathrm{~s}$ from the group account. If the computer does not monitor the round, or if the round is monitored but you are not the lowest investor in the Group account, then your total E\$s earned would be 8 (from your Individual account) +10 (from the group account) $=18$ total $\mathrm{E} \$$ s earned.

However, if the round was monitored and you were the lowest investor in the Group account, then your final earnings in this round would be deducted by some amount, (from the chart, as OG-G $=6-2=4$, the payoff cut percentage is $4 \%$ ), so the payoff cut amount will be $18 \times 4 \%=0.72$ and then your total earnings in this round would be $18-0.72=17.28 \mathrm{E} \$$

\section{How to Make Your Decisions in Each Round}

You will make decisions by entering numbers into boxes on your computer screen (If you want to see what the screen looks like, please click the button on the left corner and you will be able to return to the instructions by clicking "Click for instructions" button). The screen will also give you important messages and other information. It is important that you understand the information on the screen. If after reading these instructions you still do not understand your screen, then please raise your hand and an experimenter will assist you.

The round number appears in the top left corner of the screen. In this experiment there will be exactly 30 rounds. The screen will show you both the current round, and how many rounds there 
are in this experiment in total.

The upper left part of the screen also includes a box that shows your "endowment," which is the number of $\mathrm{E} \$$ that you are given each round. In this experiment your endowment is $10 \mathrm{E} \$$ each round. You have to decide on the number of E\$ to place in both the Individual and in the Group accounts.

To invest in the Individual account, use the mouse to move your cursor to the box labeled "Individual Account", click on the box and enter the number of E\$ you wish to allocate to this account. Do the same for the box labeled "Group Account" to make your group investment. Entries in the two boxes must be positive whole numbers that sum to your endowment (10 E\$). To change any of your entries, use the mouse to select what you have previously typed in that box and simply overwrite. To submit your investment, click on the "Submit" button. Once you have done this, your decision can no longer be revised. You will then wait until everyone else has submitted his or her investment decisions.

\section{Seeing your results}

Once every member of your group has entered a decision, the outcome of the round will be displayed directly below the boxes where you entered your investment amounts. There are two information boxes on the left. One is the "Payoff Cut Message", from which you will see whether your payoff will be cut by some amount. Again, this message only shows you whether you received a payoff cut or not. You won't know whether any other of your group members received a payoff cut. Similarly, your group members will not know whether you received payoff cut.

The other information box is labeled "Outcome of This Round" and will show you:

(1) how much each of your group members invested in the Group

Account (IDs are NOT listed);

(2) your Individual investment(I) and Group investment(G);

(3) the difference between your $\mathbf{G}$ and the average investment amount of your other 3 group members( OG ). This is listed in the column titled as $\mathbf{O G}-\mathbf{G}$;

(4) if you received a payoff cut, the payoff cut amount;

(5) your final earnings for this round.

You can move your mouse to the information box and it will extend to display all of this information.

The History Record on the left side of the window records the data from all of the rounds you've played so that you can review previous rounds' outcomes anytime. Again, you might need to move your mouse to the box to see the complete information. You might also have to scroll up to see early records. The right bottom box will show you the current status of the experiment. In addition, several important things to know about the experiment will be listed there for your easy reference.

After you finish reading the information, please click the "Click when ready" button. Once every 
subject clicks the button, you will begin the next round.

At the end of the experiment, your E\$s earned in each period will be added together, and you will be paid privately at the rate $20 \mathrm{E} \$=\$ 1$.

\section{Summary}

1. Your task: Decide how to invest your 10E $\$$ in each round.

2. Monitoring: Each round has 50\% chance being monitored. If monitored, the lowest Group account investor will receive a payoff cut.

3. The amount of payoff cut percentage is determined by the difference between the average of your other 3 group members' Group account investment (OG) and your Group account investment $(G)$. When the difference OG-G is bigger, the payoff cut (if any) will be larger.

4. At the end of each round, each member will be informed whether he/she received a payoff cut. No investor will know if a different member received a payoff cut.

\section{Public Punishment Treatment}

Thank you for coming! You've earned \$5 for showing up on time, and the instructions explain how you make decisions to earn more money. So please read these instructions carefully! There is no talking at any time during this experiment. If you have a question please raise your hand, and an experimenter will assist you.

The experiment is divided into different rounds. In all, the experiment consists of 30 rounds. You will be randomly assigned to a group with 3 other participants. The composition of each group will NOT change during the experiment. You won't know the identities of your group members.

At the beginning of each round each participant receives 10 E\$. At the end of the experiment the total number of $\mathrm{E} \$$ you have earned will be converted to dollars at the following rate:

$$
20 \mathrm{E} \$=\$ 1
$$

In each round, you will decide how to allocate your E\$s. After each member in your group makes her decision, the computer will randomly decide whether to monitor the group this round or not. If the group is monitored, then one person in that round might receive a payoff cut. Additional information about the monitoring and payoff cuts is given below.

At the beginning of each round, you decide how many of your $10 \mathrm{E} \$$ to invest in the Group Account(G) and how many to invest in your Individual Account ( I ). These two accounts are explained below.

\section{Individual Account ( I)}

Every E\$ you assign to the Individual account will return one E\$ at the end of the round.

For example, if you invested all 10E $\$$ in your Individual account, you would earn 10E $\$$ from the individual account at the end of the round. If you invested 5E $\$$ in your Individual account, you 
would earn 5E\$ from the individual account at the end of the round.

\section{Group Account (G)}

Your earnings from the Group Account depend on the number of E\$ that you and your other group members invest in the Group Account. All E\$s that you and your group members invest in the Group account are added together and form the group investment. The group investment generates return of $2 \mathrm{E} \$$ for every one E\$ invested. These earnings are then divided equally among all group members. Your group has 4 members (including yourself). So, every E\$ invested in the Group account will return half of an $\mathbf{E} \mathbf{\$}$ to each group member at the end of the round.

Some examples of returns to group investment are illustrated in the table below. The left column lists various amounts of group investment; the right column contains the corresponding personal earnings for each group member:

\begin{tabular}{cc}
$\begin{array}{l}\text { Total Group investment amount } \\
\text { by your group (TG) }\end{array}$ & $\begin{array}{l}\text { Return to each group member } \\
\text { (from Group investment) }\end{array}$ \\
\hline 0 & 0 \\
8 & 4 \\
10 & 5 \\
14 & 7 \\
28 & 14 \\
40 & 20 \\
\hline
\end{tabular}

As you can see, it does not matter who invests $\mathrm{E} \$ \mathrm{~s}$ in the Group account. Everyone will get the same return from every $\mathrm{E}$ \$ invested there-whether they invested $\mathrm{E} \$$ in the Group account or not.

\section{Monitoring}

After all members of your group have made their decisions, the computer will randomly decide whether to monitor the round. Each round has a $\mathbf{5 0 \%}$ chance of being monitored, and whether a round is monitored does not depend on whether other rounds were or were not monitored.

Here is what monitoring means. If the round is monitored, then the lowest investor in the Group Account will have his or her payoff for that round cut by some amount. If two or more group members invest the same lowest amount in the Group Account, then the computer will randomly choose one of them to receive the payoff cut. If all the group members invest all their $10 \mathrm{E} \$$ to the Group account, no one will receive a payoff cut when the round is monitored.

\section{Payoff cut}

Here is how the payoff cut amount is determined. When a subject's payoff is cut, his or her payoff in that round will be reduced by a certain percentage. This percentage is determined by the difference between his/her Group investment (G) and the average Group investment of his/her other three group members (OG). The specific formula used to determine the amount of the 
payoff cut is:

\section{Payoff cut Percentage $=($ OG-G $) \%$}

Payoff Cut $=$ Original Payoff $($ before cut $) \times$ Payoff cut Percentage

You have been given a chart that shows the payoff cut percentage for different values of $\mathbf{G}$ and OG. From the chart you can see that the payoff cut percentage becomes increasingly larger as G becomes increasingly smaller than OG. Please raise your hand if you do not understand this chart.

Example: If a subject receives a payoff cut, his/her Group investment is 2 and other three members' average Group investment is 6 , then his/her payoff cut percentage will be $(\mathbf{6}-2) \%=4 \%$. You can double check this answer with the chart. It shows that when OG-G=4, the payoff cut percentage $=4 \%$. This means that $4 \%$ of the subject's original payoff (for that round only) will be cut.

If a subject receives a payoff cut, his/her Group investment is 1 and other three members' average Group investment is 7, then his/her payoff cut percentage will be (7-1)\%=6\%. You can double check with the chart which shows that when $\mathbf{O G - G}=6$, the payoff cut percentage $=6 \%$. This also means that $6 \%$ of the original payoff will be cut in that round.

Important: Each round you will be told whether you received a payoff cut. In addition, you will know if the least group account investor's payoff was cut.

\section{Your earnings in each round}

The total E\$s you earn at the end of each round is the sum of your earnings from each of the two accounts:

1) $\mathrm{E} \$$ s earned from your Individual account = amount of $\mathrm{E} \$ \mathrm{~s}$ you invest in the Individual account.(I)

2) $\mathrm{E} \$$ s earned from the Group account $=0.5 \times$ the total invested $\mathrm{E} \$ \mathrm{~s}$ of all 4 Group members to this account.(TG)

So your earnings at the end of each round $=$

$\mathbf{I}+0.5 \times \mathbf{T G}$, if there is no payoff cut, and

I + 0.5×TG - Payoff Cut amount, if there is a payoff cut.

\section{Example}

Suppose that you invested $8 \mathrm{E} \$ \mathrm{~s}$ in your Individual account and $2 \mathrm{E} \$ \mathrm{~s}$ in the Group account, and the three other members invested a total of $18 \mathrm{E} \$ \mathrm{~s}$ in the group account. This means there is a total of $20 \mathrm{E} \$ \mathrm{~s}$ in the group account. Then your earnings from the Group account would be $20 * 0.5=10 \mathrm{E} \$$. Each other subject in your group would also earn $10 \mathrm{E} \$ \mathrm{~s}$ from the group account. If the computer does not monitor the round, or if the round is monitored but you are not the lowest investor in the Group account, then your total E\$s earned would be 8 (from your Individual account) +10 (from the group account) $=18$ total E\$s earned.

However, if the round was monitored and you were the lowest investor in the Group account, then your final earnings in this round would be deducted by some amount, (from the chart, as 
OG-G $=6-2=4$, the payoff cut percentage is $4 \%$ ), so the payoff cut amount will be $18 \times 4 \%=0.72$ and then your total earnings in this round would be $18-0.72=17.28 \mathrm{E} \$$

\section{How to Make Your Decisions in Each Round}

You will make decisions by entering numbers into boxes on your computer screen (If you want to see what the screen looks like, please click the button on the left corner and you will be able to return to the instructions by clicking "Click for instructions" button). The screen will also give you important messages and other information. It is important that you understand the information on the screen. If after reading these instructions you still do not understand your screen, then please raise your hand and an experimenter will assist you.

The round number appears in the top left corner of the screen. In this experiment there will be exactly 30 rounds. The screen will show you both the current round, and how many rounds there are in this experiment in total.

The upper left part of the screen also includes a box that shows your "endowment," which is the number of E\$ that you are given each round. In this experiment your endowment is 10E\$ each round. You have to decide on the number of $\mathrm{E} \$$ to place in both the Individual and in the Group accounts.

To invest in the Individual account, use the mouse to move your cursor to the box labeled "Individual Account", click on the box and enter the number of E\$ you wish to allocate to this account. Do the same for the box labeled "Group Account" to make your group investment. Entries in the two boxes must be positive whole numbers that sum to your endowment (10 E\$). To change any of your entries, use the mouse to select what you have previously typed in that box and simply overwrite. To submit your investment, click on the "Submit" button. Once you have done this, your decision can no longer be revised. You will then wait until everyone else has submitted his or her investment decisions.

\section{Seeing your results}

Once every member of your group has entered a decision, the outcome of the round will be displayed directly below the boxes where you entered your investment amounts. There are two information boxes on the left. One is the "Payoff Cut Message", from which you will see whether your payoff will be cut by some amount. Again, this message shows you not only whether you received a payoff cut but also whether any other of your group members received a payoff cut. Similarly, every one of your group members will know whether anyone received a payoff cut.

The other information box is labeled "Outcome of This Round" and will show you:

(1) how much each of your group members invested in the Group

Account (IDs are NOT listed);

(2) your Individual investment(I) and Group investment(G);

(3) the difference between your $\mathbf{G}$ and the average investment amount of your other 3 group members( OG ). This is listed in 
the column titled as $\mathbf{O G - G}$;

(4) if you received a payoff cut, the payoff cut amount;

(5) your final earnings for this round.

You can move your mouse to the information box and it will extend to display all of this information.

The History Record on the left side of the window records the data from all of the rounds you've played so that you can review previous rounds' outcomes anytime. Again, you might need to move your mouse to the box to see the complete information. You might also have to scroll up to see early records. The right bottom box will show you the current status of the experiment. In addition, several important things to know about the experiment will be listed there for your easy reference.

After you finish reading the information, please click the "Click when ready" button. Once every subject clicks the button, you will begin the next round.

At the end of the experiment, your E\$s earned in each period will be added together, and you will be paid privately at the rate $20 \mathrm{E} \$=\$ 1$.

\section{Summary}

1. Your task: Decide how to invest your 10E\$ in each round.

2. Monitoring: Each round has $50 \%$ chance being monitored. If monitored, the lowest Group account investor will receive a payoff cut.

3. The amount of payoff cut percentage is determined by the difference between the average of your other 3 group members' Group account investment (OG) and your Group account investment $(G)$. When the difference OG-G is bigger, the payoff cut (if any) will be larger.

4. At the end of each round, each member will be informed whether anyone in his/her group received a payoff cut. 